\title{
Energy and Environmental Efficiency of China's Transportation Sector: A Multidirectional Analysis Approach
}

\author{
Gongbing Bi, Pingchun Wang, Feng Yang, and Liang Liang \\ School of Management, University of Science and Technology of China, No. 96 Jinzhai Road, Hefei, Anhui 230026, China \\ Correspondence should be addressed to Feng Yang; fengyang@ustc.edu.cn
}

Received 19 March 2014; Accepted 14 April 2014; Published 12 May 2014

Academic Editor: X. Zhang

Copyright (C) 2014 Gongbing Bi et al. This is an open access article distributed under the Creative Commons Attribution License, which permits unrestricted use, distribution, and reproduction in any medium, provided the original work is properly cited.

\begin{abstract}
With the rapid economic development, the transportation sector becomes one of the high-energy-consumption and high- $\mathrm{CO}_{2}-$ emissions sectors in China. In order to ensure efficient use of energy and to reduce $\mathrm{CO}_{2}$ pollution, it is important to gain the best performance standards in China's transportation sector. Data envelopment analysis (DEA) has been accepted as a popular tool of efficiency measurement. However, previous studies based on DEA are mainly restricted to the radial expansions of outputs or radial contractions of inputs. In this paper, we present a nonradial DEA model with multidirectional efficiency analysis (MEA) involving undesirable outputs for the measurement of regional energy and environmental efficiency of China's transportation sector during the period 2006-2010. We not only evaluate the energy and environmental efficiency level and trend of China's transportation sector but also investigate the efficiency patterns of 30 regions and three major areas of China. Additionally, we identify the energy saving potential and $\mathrm{CO}_{2}$ emissions reduction potential for each province and area in China in this study.
\end{abstract}

\section{Introduction}

After the rapid growth of China's economy in the past three decades, the increasing energy consumption, the carbon dioxide $\left(\mathrm{CO}_{2}\right)$ emissions, and environmental pollution are currently hindering the sustainability of China's economic growth. Since 2007, China has already surpassed the USA and become the world's largest energy consumer and contributor of $\mathrm{CO}_{2}$ emissions [1]. To address this issue, China's 12th fiveyear plan seeks to establish a "green, low-carbon development concept." [2]. In 2015, China will increase the proportion of nonfossil fuels in energy generation to $11.4 \%$, reduce energy consumption per unit of gross domestic product (GDP) by $16 \%$, and reduce $\mathrm{CO}_{2}$ emissions per unit of GDP by $17 \%$ from the levels in 2010 [2].

Recognizing the great significance of reducing energy consumption and $\mathrm{CO}_{2}$ emissions as well as sustainable development, more and more researchers have focused on evaluating and improving energy utilization and $\mathrm{CO}_{2}$ emissions efficiency, which is considered as a crucial way to save energy, reduce greenhouse gas emissions, protect environment, and mitigate global climate change [3-8]. These studies mainly focused on the energy or environmental efficiency of industries such as electricity, iron, and steel. However, few papers have considered the energy and environmental efficiency evaluation of China's transportation sectors.

According to the International Energy Agency (IEA) [9], we found that transport sector consumed $61.2 \%$ of the world's oil and approximately $28 \%$ of the total final energy in 2007 and the transport sector had become the world's largest oil consumption sector. According to the International Energy Agency (IEA) [10], transport sector became the world's second largest greenhouse gas emitting sector which accounted for $22 \%$ of the world's $\mathrm{CO}_{2}$ emissions. Thus, we take for granted that it is worthwhile analyzing the energy and environmental efficiency of transportation sector in the largest polluting country of the world since it provides a lot of information on energy and environmental policy analysis and decision making.

The indexes of energy or environmental performance are constructed in the form of mathematics programming methods such as data envelopment analysis (DEA). As a nonparametric approach to evaluate the relative efficiency of a set of comparable decision making units (DMUs), DEA, which was developed by Charnes et al. [11], has been widely investigated and popularly applied to many fields, 
such as schools, hospital, and banks [12, 13]. Recently, at the macroeconomy level, DEA has been universally used in studying the energy and environmental performance in examining the relative efficiency [14]. For instance, $\mathrm{Hu}$ and Wang [15] adopted the traditional Charnes-Cooper-Rhodes (CCR) model to evaluate the total-factor energy efficiency of 29 regions in China during 1995-2002. Zhang et al. [16] analyzed the industrial sectors' ecoefficiency of 30 provinces in China by a DEA model and found that most Chinese regions with higher levels of GDP per capital would have higher ecoefficiency. Yeh et al. [7] incorporated undesirable outputs into calculating the technical efficiency of energy utilization in Chinese mainland and Taiwan during the period of 20022007 through employing the traditional Banker-CharnesCooper (BCC) model. Shi et al. [17] used three extended DEA models to investigate the energy and environmental overall technical efficiency, pure technical efficiency, and scale efficiency of industry sectors in 28 regions of China during 2000-2006, with the undesirable output of industrial waste gas being treated as inputs in energy and environmental efficiency analysis. Bian and Yang [6] presented several DEA models for calculating resource and environmental efficiency and applied their proposed approach in real data set of 30 provinces in China. Wang et al. [18] adopted a traditional DEA to analyze the industrial sectors' energy efficiency in China's 30 provinces during the period of 2005-2009. Their study showed that the west area had the greatest amount of energy redundancies in the three major areas. Wang et al. [19] established several efficiency models which were capable of integrating undesirable outputs into efficiency measure framework to evaluate the economic efficiency, $\mathrm{CO}_{2}$ emissions efficiency, and economic-environmental efficiency of 28 provinces in China from 2001 to 2007. Similar studies also can be found in [5, 20-23].

However, most of the previous studies on energy and environmental efficiency mentioned above took advantage of the traditional DEA approach, in which the DMUs under measurement were restricted to the radial constraints on input and output variables. In this study, we take multidirectional efficiency analysis (MEA) instead of the traditional radial DEA approach. MEA selects benchmarks such as the input reductions and the output expansions are proportional to the potential improvements related to each input and output dimension separately. It enables us to have a specific insight of the patterns of efficiencies for each DMU. The traditional MEA approach does not always consider the undesirable outputs. Although Asmild and Matthews [24] and Wang et al. [1] used the approach and took the undesirable outputs as input, it was inappropriate to reflect the actual production process since undesirable outputs were produced as the byproducts of production process rather than the input. Thus we adopt the environmental DEA technology proposed by Fare et al. [25] as the alternative approach to model undesirable outputs. Meanwhile, traditional MEA model presents the fact that the input reductions and output expansions have the same proportion to the potential improvements identified considering the improvement potential related to each input and output variable separately. But it is still treated as a radial measure of efficiency. Since the radial model adjusts all variables to efficient targets by the same proportion, it cannot provide information regarding the efficiency of the specific inputs or outputs involved in the production process [26]. At the same time, radial efficiency measures may neglect the slack variables, leading to efficiency overestimation [27]. As a result, recent studies have tried to use the nonradial DEA model $[26,28-30]$ to overcome these problems. So we follow the same pattern and adjust the MEA model to make input reductions and the output expansions nonproportional to the potential improvements related to each input and output dimension separately.

As for the transportation sector, Ramanathan [31] used DEA to measure the energy efficiency of alternative transport modes in India. Tongzon [32] also assessed the efficiency of four Australian and twelve international container ports based on DEA. However, all these studies in the transportation sector did not involve undesirable outputs in estimating efficiency. In order to investigate the levels and the patterns of efficiency in China's transportation sector and provide additional insights into the energy and emissions efficiency of each China's region, hence our study will use the modified MEA model and consider undesirable outputs.

The rest of this paper is organized as follows. Section 2 introduces the environmental production technologies and outlines the methodology of modified MEA model. In Section 3, we show an empirical study of China's 30 regions in transportation sector during 2006-2010 to illustrate our model. Section 4 gives discussions and conclusions.

\section{Methodology}

2.1. Environmental Production Technology. Let us consider a production process that consumes a vector of inputs $\mathbf{x}$ to obtain a vector of desirable outputs $\mathbf{y}$ and a set of undesirable outputs denoted by the vector $\mathbf{c}$. Then a production technology is given by

$$
T=\{(\mathbf{x}, \mathbf{y}, \mathbf{c}): \mathbf{x} \text { can produce }(\mathbf{y}, \mathbf{c})\} .
$$

Following Färe et al.s [33] approach, we treat by-products as outputs and accept the following three assumptions which are imposed on the production technology.

(1) Strong or free disposability of desirable outputs: it implies that if $(\mathbf{x}, \mathbf{y}, \mathbf{c}) \in T$ and $\mathbf{y}^{*} \leq \mathbf{y}$, then $\left(\mathbf{x}, \mathbf{y}^{*}, \mathbf{c}\right) \in T$. This allows for the assumption that if an observed desirable and undesirable output vector are possible, then each output vector with a smaller desirable output is also feasible. It implies that we can always freely dispose of some desirable outputs without undertaking any cost.

(2) Weak disposability of undesirable outputs: if $(\mathbf{x}, \mathbf{y}, \mathbf{c}) \in T$ and $0 \leq \theta \leq 1$, then $(\mathbf{x}, \theta \mathbf{y}, \theta \mathbf{c}) \in T$. This means that the proportional reduction in desirable and undesirable outputs is possible, whereas it may be costly to reduce undesirable outputs and these abatement activities will usually divert resources away from desirable outputs. The assumption is to introduce the idea that it is not feasible to reduce undesirable outputs solely. 
(3) Desirable and undesirable outputs being null-joint: if $(\mathbf{x}, \mathbf{y}, \mathbf{c}) \in T$ and $\mathbf{c}=\mathbf{0}$, then $\mathbf{y}=\mathbf{0}$. This assumption says that it is not technically feasible to produce only desirable outputs in the absence of undesirable outputs. The only way to eliminate all the undesirable outputs is to end the production process.

Once the three assumptions are imposed, $T$ is termed as environmental production technology. Suppose there are $j=$ $1,2, \ldots n$ decision making units (DMUs) which consume $m$ inputs to produce $s_{1}$ desirable outputs and $s_{2}$ undesirable outputs. Now we denote $\mathbf{x}_{j}=\left(x_{1 j}, \ldots x_{m j}\right)^{t}, \mathbf{y}_{j}=\left(y_{1 j}, \ldots y_{s_{1} j}\right)^{t}$, and $\mathbf{c}_{j}=\left(c_{1 j}, \ldots c_{s_{2} j}\right)^{t}$. as the vector of inputs, desirable outputs, and undesirable outputs of $\mathrm{DMU}_{j}$, respectively. In the DEA framework, the environmental production technology can be modeled as

$$
\begin{gathered}
T=\left\{(\mathbf{x}, \mathbf{y}, \mathbf{c}): \sum_{j=1}^{n} \lambda_{j} x_{i j} \leq x_{i j}, i=1,2, \ldots, m\right. \\
\sum_{j=1}^{n} \lambda_{j} y_{r j} \leq y_{r j}, \quad r=1,2, \ldots, s_{1} \\
\left.\sum_{j=1}^{n} \lambda_{j} c_{k j}=c_{k j}, \quad k=1,2, \ldots, s_{2}\right\} .
\end{gathered}
$$

In model (2), $\left(\lambda_{1}, \lambda_{2}, \ldots, \lambda_{j}\right)$ denotes a vector of intensity variables that form linear combinations of observed inputs and outputs with constant returns to scale not imposed by the constraint that $\sum_{j=1}^{n} \lambda_{j}=1$. The inequality on desirable outputs and equality on undesirable outputs help us to impose the strong or free disposability of desirable outputs and weak disposability of undesirable outputs.

2.2. Multidirectional Efficiency Analysis (MEA). Our aim is to gain a deeper insight into the regional energy and environmental efficiency of China's transportation by investigating the situation and analyzing the efficiency patterns in each region and area. More specifically, we measure the comprehensive efficiency incorporating $\mathrm{CO}_{2}$ emissions and energy efficiency of China's regional transportation sector. In this study, we will use multidirectional efficiency analysis (MEA) instead of the traditional radial DEA approach, which enables us to have a specific view of the patterns of efficiencies.

Multidirectional efficiency analysis was firstly proposed by Bogetoft and Hougaard [34], further developed by Bogetoft and Hougaard [35] and Asmild and Pastor [36]. Previous studies $[24,37,38]$ did not take the undesirable outputs into account by using MEA. In this paper we will make full use of this approach and consider the undesirable outputs simultaneously. It is able to select benchmarks such as the inputs, undesirable outputs reduction, and desirable outputs augmentation, which are not proportional to the actual production, but proportional to the potential improvements related to each input and output variable separately. In addition, since MEA considers the improvement potential in each variable separately, it is very suitable to investigate situations, where the purpose is to reduce the consumptions of some inputs and the emission of some undesirable outputs and to expand the production of some desirable outputs. Furthermore, since efficiency improvements in the present case were derived from a combination of the inputs consumed reduction and the desirable outputs production increment, as well as the undesirable outputs emission abatement, we see it a better way to adopt the MEA approach to achieve the efficiency improvements.

In the general case of considering reductions of all inputs and undesirable outputs simultaneously with augmentations of all of desirable outputs in MEA, we define the unit specific directional distance function on the basis of the unit specific ideal reference point. In order to find the ideal reference point, we firstly solve the following linear programs, one for each of input dimensions, desirable output dimensions, and undesirable output dimensions, respectively:

$$
\begin{aligned}
& \min d_{i o} \\
& \text { s.t. } \quad \sum_{j=1}^{n} \lambda_{j} x_{i j} \leq d_{i o} \text {, } \\
& \sum_{j=1}^{n} \lambda_{j} x_{-i j} \leq x_{-i o}, \quad-i=1, \ldots, i-1, i+1, \ldots m \\
& \sum_{j=1}^{n} \lambda_{j} y_{r j} \geq y_{r o}, \quad r=1, \ldots, s 1 \\
& \sum_{j=1}^{n} \lambda_{j} c_{k j}=c_{k o}, \quad k=1, \ldots, s 2 . \\
& \lambda_{j} \geq 0, \quad j=1, \ldots, n,
\end{aligned}
$$

$$
\begin{array}{ll}
\min & \varphi_{k o} \\
\text { s.t. } & \sum_{j=1}^{n} \lambda_{j} c_{k j}=\varphi_{k o} \\
& \sum_{j=1}^{n} \lambda_{j} c_{-k j}=c_{-k o}, \quad-k=1, \ldots, k-1, k+1, \ldots, s 2
\end{array}
$$




$$
\begin{gathered}
\sum_{j=1}^{n} \lambda_{j} x_{i j} \leq x_{i o}, \quad i=1, \ldots, m \\
\sum_{j=1}^{n} \lambda_{j} y_{r j} \geq y_{r o}, \quad r=1, \ldots, s 1 \\
\lambda_{j} \geq 0, \quad j=1, \ldots, n .
\end{gathered}
$$

By solving the model $(3 \mathrm{a})-(3 \mathrm{c})$, we are able to determine the ideal reference point $\left(d_{i o}^{*}, \delta_{r o}^{*}, \varphi_{k o}^{*}\right)$ for $\left(x_{i o}, y_{r o}, c_{k o}\right)$, where $*$ denotes the optimal solutions of model (3a)-(3c). With the unit specific ideal point determined, we next consider the following linear programming model (4):

$$
\begin{array}{ll}
\max & \beta_{\mathrm{o}} \\
\text { s.t. } & \sum_{j=1}^{n} \lambda_{j} x_{i j} \leq x_{i o}-\beta_{o}\left(x_{i o}-d_{i o}^{*}\right), \quad i=1, \ldots, m \\
& \sum_{j=1}^{n} \lambda_{j} y_{r j} \geq y_{r o}+\beta_{o}\left(\delta_{r o}^{*}-y_{r o}\right), \quad r=1, \ldots, s 1 \\
& \sum_{j=1}^{n} \lambda_{j} c_{k j}=c_{k o}-\beta_{o}\left(c_{k o}-\varphi_{k o}^{*}\right), \quad k=1, \ldots, s 2 \\
& \lambda_{j} \geq 0, \quad j=1, \ldots, n,
\end{array}
$$

where $\beta_{o}$ represents the productive technical inefficiency of $\mathrm{DMU}_{0}$ and also measures the proportion by which the desirable outputs are added while the undesirable outputs and inputs are contracted in the same proportion. The value of $\beta_{o}$ belongs to the interval $[0,1]$. If $\beta_{o}=0$, it means that the evaluated DMU reaches to the frontier of the best practice and is therefore efficient.

From model (4), we find that the inputs and undesirable outputs reduction and desirable outputs expansion have the same proportion to the potential improvements identified considering the improvement potential related to each input and output variable separately. So it may still be treated as a radial measure of efficiency. However, radial efficiency measures overestimate the efficiency when there exist nonzero slacks. Based on this, we will modify model (4) and make the inputs and outputs be adjusted nonproportionally. Next, we will form model (5):

$$
\begin{array}{ll}
\max & \beta_{i o}+\beta_{r o}+\beta_{k o} \\
\text { s.t. } & \sum_{j=1}^{n} \lambda_{j} x_{i j} \leq x_{i o}-\beta_{i o}\left(x_{i o}-d_{i o}^{*}\right), \quad i=1, \ldots, m \\
& \sum_{j=1}^{n} \lambda_{j} y_{r j} \geq y_{r o}+\beta_{r o}\left(\delta_{r o}^{*}-y_{r o}\right), \quad r=1, \ldots, s 1 \\
& \sum_{j=1}^{n} \lambda_{j} c_{k j}=c_{k o}-\beta_{k o}\left(c_{k o}-\varphi_{k o}^{*}\right), \quad k=1, \ldots, s 2 \\
& \lambda_{j} \geq 0, \quad j=1, \ldots, n .
\end{array}
$$

We are able to get an optimal solution by solving model (5). Then we define the relative variable specific MEA efficiency for every variable separately.

For the input variable $x_{i o}$, we are able to define specific input MEA efficiency as follows:

$$
\frac{x_{i o}-\beta_{i o}\left(x_{i o}-d_{i o}^{*}\right)}{x_{i o}} .
$$

For the desirable output $y_{r o}$, we are able to define specific desirable output MEA efficiency as follows:

$$
\frac{y_{r o}}{y_{r o}+\beta_{r o}\left(\delta_{r o}^{*}-y_{r o}\right)} \text {. }
$$

For the undesirable output $c_{k o}$, we are able to define specific undesirable output MEA efficiency as follows:

$$
\frac{c_{k o}-\beta_{k o}\left(c_{k o}-\varphi_{k o}^{*}\right)}{c_{k o}} .
$$

By defining each of MEA efficiencies for every variable, we focus on the pattern of the individual specific variable efficiencies. For instance, we pay attention to the efficiency of energy and environment in China's transportation. Based on the individual variable specific efficiencies, we require a comprehensive measure of efficiency for the measured DMUs. Färe and Knox lovell [39] firstly proposed Russell graph measure which is a comprehensive efficiency measure. This remains as a theoretical contribution and still inspires most of the following comprehensive efficiency measures. For example, many DEA efficiency assessments have been proposed based on the additive model [40], which detect all the technical inefficiency in all dimensions such that the benchmarks lie on the strong efficiency and do not have any slacks [41-44]. Now we will use the same comprehensive measure as the SBM model of Tone [44] to combine the inefficiencies in the different dimensions into one overall value. And the overall score of MEA efficiency for the observation of $\mathrm{DMU}_{0}$ can be defined as follows:

$$
\begin{aligned}
\theta_{o}=\left(1-\frac{1}{m} \sum_{i=1}^{m} \frac{\beta_{i o}\left(x_{i o}-d_{i o}^{*}\right)}{x_{i o}}\right) \\
\times\left(1+\frac{1}{s 1+s 2}\right. \\
\times\left(\sum_{r=1}^{s 1} \frac{\beta_{r o}\left(\delta_{r o}^{*}-y_{r o}\right)}{y_{r o}}\right. \\
\left.\left.\quad+\sum_{k=1}^{s 2} \frac{\beta_{k o}\left(c_{k o}-\varphi_{k o}^{*}\right)}{c_{k o}}\right)\right)^{-1} .
\end{aligned}
$$

Unlike the original MEA efficiency, the comprehensive measure (9) has the desirable characteristic that the resulting value incorporates all variables.

\section{Empirical Studies}

3.1. Data and Variables. This study will examine the energy and environmental efficiency of China's transportation sector 
TABle 1: Areas and regions of China (excluding Tibet).

\begin{tabular}{ll}
\hline Areas & Regions \\
\hline East area & Beijing, Tianjin, Shanghai, Liaoning, Hebei, Shandong, Jiangsu, Zhejiang, Fujian, Guangdong, and Hainan \\
Central area & Heilongjiang, Jilin, Inner Mongolia, Henan, Shanxi, Anhui, Hubei, Hunan, Jiangxi, and Guangxi \\
West area & Gansu, Guizhou, Ningxia, Qinghai, Shaanxi, Yunnan, Xinjiang, Sichuan, and Chongqing \\
\hline
\end{tabular}

TABLE 2: $\mathrm{CO}_{2}$ emissions factor by major carbonaceous fuel types in China (source: NDRC, 2007 [50]).

\begin{tabular}{lcccccc}
\hline Fuels & Coal & Petrol & Kerosene & Diesel & Fuel oil & Nature gas \\
\hline CCF & 27.28 & 18.9 & 19.6 & 20.17 & 21.09 & 15.32 \\
HE & 192.14 & 448 & 447.5 & 433.3 & 401.9 & 0.384 \\
COF $(\%)$ & 92.3 & 98.0 & 98.6 & 98.2 & 98.5 & 99.0 \\
\hline
\end{tabular}

Notes: CCF and HE are expressed in units of tons, carbon/trillion Joules, and trillion Joules $/ 10^{4}$ tons $\left(\mathrm{m}^{3}\right)$, respectively.

of 30 provinces in mainland during the 11th five-year plan period (2006-2010). From the perspective of China's development and policy factors, these provinces and autonomous regions are divided into three areas: east, central, and west China [15]. Detailed information is shown in Table 1.

Tibet is excluded since the absence of relevant data in this research. According to China's Statistical Yearbooks, the transportation sector in China is defined as consisting of transport, storage, and post. So we will follow this definition to collect the relevant data. In our study, three inputs, one desirable output, and one undesirable output are considered to measure the energy and environmental efficiency in China's transportation sector. Therefore the labor and capital stocks are used as two nonenergy inputs, the volume of energy consumed in the transportation sector as energy input, a value-added amount in the transportation sector as the only desirable output, and the volume of $\mathrm{CO}_{2}$ emissions related to fuel used in the sector as undesirable output. Since there is no capital stock statistics data in China, we will use the amount of fixed capital investment to represent capital stock as some authors did $[6,17,45,46]$. The total energy consumption includes all types of energy, such as coal, oil, natural gas, and electricity. We will convert these energies to the tonne coal equivalent (tce).

The data of nonenergy inputs (labor and the fixed capital investment), energy input, and desirable output (a valueadded) are available from China Statistical Yearbook 20072011 [47] and China Energy Statistical Yearbook 2007-2011 [48]. Unfortunately, there are still no official statistical data on $\mathrm{CO}_{2}$ emissions in China. Thereby we will estimate the provincial $\mathrm{CO}_{2}$ emissions in the transportation sector during 2006-2010 based on a fuel-based carbon footprint model, as described by the Intergovernmental Panel on Climate Change Guidelines [49] for National Greenhouse Gas Inventories for calculating $\mathrm{CO}_{2}$ data. According to these guidelines for estimating $\mathrm{CO}_{2}$ emissions, the equation for calculating $\mathrm{CO}_{2}$ emissions from fossil fuels appeared as follows:

$$
\mathrm{CO}_{2}=\sum_{i=1}^{n} A \times \mathrm{CCF}_{i} \times \mathrm{HE}_{i} \times \mathrm{COF}_{i} \times\left(\frac{44}{12}\right) .
$$

From (10), we know that $\mathrm{CO}_{2}$ emissions are related to the amount of all carbonaceous fuel combusted $(A)$, the carbon content factor (CCF), the heat equivalent (HE), and the carbon oxidation factor (COF) of carbonaceous fuel. The number (44/12) is the ratio of the molecular weight of $\mathrm{CO}_{2}$ (44) to the molecular weight of carbon (12), where $\mathrm{CCF}_{i} \times$ $\mathrm{HE}_{i} \times \mathrm{COF}_{i} \times(44 / 12)$ is the $\mathrm{CO}_{2}$ emissions factor of a fuel. As long as we know the amount and the $\mathrm{CO}_{2}$ emissions factor of each fuel, the total $\mathrm{CO}_{2}$ emissions of each province can be calculated. The amount of consumption of each fuel of each province in the transportation sector is collected from China Energy Statistical Yearbook 2007-2011. The Energy Research Institute (ERI) of National Development and Reform Commission (NDRC) [50] of China reported the $\mathrm{CO}_{2}$ emissions factor by major type of carbonaceous fuels in China, as is shown in Table 2. Then we will figure out the total $\mathrm{CO}_{2}$ emissions based on the formula of IPCC guidelines.

After collecting the related data on the three inputs, one desirable output, and one undesirable output, a data set encompassing 30 provinces during 2006-2010 is prepared for analysis in Table 3 . A correlation matrix of all inputs and outputs is calculated for verifying the relationship between the inputs and outputs variables. Table 4 shows the result that all the correlation coefficients in the table are significantly positive, which indicates that a quite high correlation exists among every variable. Thus, energy and environmental efficiency analysis in this case is feasible.

\subsection{Efficiency Levels of China's Region in Transportation} Sector. First we use models (5) and (9) to evaluate the comprehensive MEA efficiency score of different provinces in China's transportation sector from 2006 to 2010, and the related result is shown in Table 5 . We find that the average comprehensive MEA efficiencies of about $70 \%$ regions are below 0.5, with Yunnan ranking lowest and Hebei ranking highest during 2006-2010. There are only 3 regions exhibiting MEA efficient at least 1 year during 2006-2010. Only Hebei performed best in keeping efficient during the whole study period. Shandong also performed well and was assessed as efficient region for 4 years except 2010. The result indicates that large parts of the regions in China are not performing efficiently in the transportation sector. Hence, there is a great possibility to reduce the energy consumption and $\mathrm{CO}_{2}$ 
TABLE 3: Descriptive statistics of inputs and outputs for 30 regions.

\begin{tabular}{|c|c|c|c|c|c|c|}
\hline Inputs and outputs & Year & 2006 & 2007 & 2008 & 2009 & 2010 \\
\hline \multirow{4}{*}{ Labor $\left(10^{4}\right.$ peoples $)$} & Mean & 20.4 & 20.7 & 20.9 & 21.1 & 21.0 \\
\hline & Standard development & 11.0 & 11.6 & 11.7 & 12.2 & 12.4 \\
\hline & Maximum & 48.3 & 48.8 & 49.3 & 53.5 & 56.1 \\
\hline & Minimum & 2.9 & 2.8 & 2.8 & 3.0 & 2.9 \\
\hline \multirow{4}{*}{ Capital $\left(10^{8}\right.$ yuan $)$} & Mean & 363.7 & 409.7 & 468.5 & 671.1 & 821.1 \\
\hline & Standard development & 210.9 & 221.8 & 246.8 & 348.0 & 431.9 \\
\hline & Maximum & 865.0 & 862.5 & 1108.8 & 1596.2 & 1820.0 \\
\hline & Minimum & 51.3 & 48.9 & 90.1 & 90.1 & 120.9 \\
\hline \multirow{4}{*}{ Energy ( $10^{4}$ TCEs $)$} & Mean & 625.4 & 698.3 & 764.4 & 811.9 & 885.2 \\
\hline & Standard development & 456.4 & 505.1 & 528.5 & 556.5 & 596.3 \\
\hline & Maximum & 1851.5 & 2042.5 & 2201.1 & 2311.5 & 2564.5 \\
\hline & Minimum & 39.9 & 71.1 & 88.2 & 98.2 & 110.5 \\
\hline \multirow{4}{*}{ Value-added $\left(10^{8}\right.$ yuan $)$} & Mean & 435.9 & 498.1 & 571.2 & 715.7 & 826.6 \\
\hline & Standard development & 307.3 & 354.8 & 429.6 & 516.7 & 606.9 \\
\hline & Maximum & 1212.3 & 1399.9 & 1873.6 & 1971.0 & 2328.4 \\
\hline & Minimum & 35.3 & 40.9 & 40.7 & 61.3 & 67.5 \\
\hline \multirow{4}{*}{$\mathrm{CO}_{2}$ emissions ( $10^{6}$ tons $)$} & Mean & 13.0 & 14.5 & 15.8 & 16.8 & 18.2 \\
\hline & Standard development & 9.6 & 10.6 & 11.1 & 11.7 & 12.4 \\
\hline & Maximum & 38.6 & 42.5 & 45.8 & 48.0 & 53.0 \\
\hline & Minimum & 0.8 & 1.5 & 1.8 & 201 & 2.3 \\
\hline
\end{tabular}

TABLE 4: Correction matrix of inputs and outputs variables.

\begin{tabular}{lcccc}
\hline & Labor & Capital & Energy & Value-added \\
\hline Labor & 1 & & & $\mathrm{CO}_{2}$ \\
Capital & $0.599^{* *}$ & 1 & & \\
Energy & $0.783^{* *}$ & $0.731^{* *}$ & 1 & 1 \\
Value-added & $0.678^{* *}$ & $0.786^{* *}$ & $0.804^{* *}$ & $0.793^{* *}$ \\
$\mathrm{CO}_{2}$ & $0.774^{* *}$ & $0.722^{* *}$ & $0.999^{* *}$ & 1 \\
\hline
\end{tabular}

** shows significant correlation at 0.01 significance level (2-tailed).

emission and to increase the value-added amounts in each region.

Then the annual average comprehensive MEA efficiency of China and its three major areas during 2006-2010 are calculated and illustrated in Figure 1. From the angle of area, the regions in east China have the highest average comprehensive MEA efficiency, followed by the regions in central China and then the regions in west China. The average comprehensive MEA efficiency of China and its three major areas basically keep first decreasing and then increasing. Also the average comprehensive MEA efficiencies of east China and central China are generally higher than those of China. And west China's average comprehensive MEA efficiency is evidently lower than the average comprehensive MEA efficiency of China. It reflects the materially unbalanced development in China's transportation sector and the gap between east and west. This result is similar to some studies about China's regional energy efficiency and environmental efficiency.
3.3. Efficiency Patterns and Differences of China's Region in Transportation Sector. The above evaluation results manifest that east China has a higher comprehensive MEA efficiency than central and west China in the transportation sector. However, the comprehensive MEA efficiency just displays the efficiency levels and the change trends of different regions and areas. We are not able to take a thorough understanding of the sources of inefficiency and to detect the patterns of efficiency differences among China's regions and three major areas in transportation sector, which are more attractive to policy makers. Therefore, it is necessary to investigate the efficiencies on individual variables of each DMU. Through the definitions (6)-(8), we calculate the relative variable specific MEA efficiencies, which enable us to survey the patterns of efficiencies in different China's regions and areas. Since this study centers on the energy and environmental efficiency, here we only figure out the energy and $\mathrm{CO}_{2}$ emissions efficiency using the definitions (6) and (8) separately.

Table 6 illustrates the relative variable specific MEA efficiency (i.e., energy and $\mathrm{CO}_{2}$ emissions efficiency) in each 
TABLE 5: Regional comprehensive MEA efficiency of China (2006-2010).

\begin{tabular}{|c|c|c|c|c|c|c|}
\hline Region & 2006 & 2007 & 2008 & 2009 & 2010 & Mean \\
\hline Beijing & 0.386 & 0.313 & 0.239 & 0.266 & 0.370 & 0.315 \\
\hline Tianjin & 0.508 & 0.438 & 0.391 & 0.514 & 0.830 & 0.536 \\
\hline Hebei & 1.000 & 1.000 & 1.000 & 1.000 & 1.000 & 1.000 \\
\hline Shanxi & 0.653 & 0.641 & 0.382 & 0.306 & 0.381 & 0.473 \\
\hline Inner Mongolia & 0.767 & 0.755 & 0.757 & 0.747 & 0.747 & 0.754 \\
\hline Liaoning & 0.328 & 0.327 & 0.283 & 0.343 & 0.367 & 0.330 \\
\hline Jilin & 0.451 & 0.388 & 0.336 & 0.321 & 0.327 & 0.365 \\
\hline Heilongjiang & 0.774 & 0.364 & 0.326 & 0.292 & 0.772 & 0.506 \\
\hline Shanghai & 0.363 & 0.297 & 0.281 & 0.703 & 0.617 & 0.452 \\
\hline Jiangsu & 0.651 & 0.619 & 0.595 & 0.814 & 1.000 & 0.736 \\
\hline Zhejiang & 0.474 & 0.484 & 0.454 & 0.423 & 0.510 & 0.469 \\
\hline Anhui & 0.922 & 0.874 & 0.869 & 0.468 & 0.525 & 0.732 \\
\hline Fujian & 0.949 & 0.917 & 0.848 & 0.516 & 0.790 & 0.804 \\
\hline Jiangxi & 0.464 & 0.482 & 0.507 & 0.448 & 0.450 & 0.470 \\
\hline Shandong & 1.000 & 1.000 & 1.000 & 1.000 & 0.826 & 0.965 \\
\hline Henan & 0.686 & 0.714 & 0.823 & 0.531 & 0.499 & 0.651 \\
\hline Hubei & 0.307 & 0.287 & 0.726 & 0.290 & 0.737 & 0.469 \\
\hline Hunan & 0.480 & 0.431 & 0.387 & 0.383 & 0.437 & 0.423 \\
\hline Guangdong & 0.462 & 0.450 & 0.382 & 0.380 & 0.420 & 0.419 \\
\hline Guangxi & 0.344 & 0.318 & 0.287 & 0.261 & 0.295 & 0.301 \\
\hline Hainan & 0.338 & 0.330 & 0.252 & 0.197 & 0.703 & 0.364 \\
\hline Chongqing & 0.426 & 0.323 & 0.287 & 0.296 & 0.312 & 0.329 \\
\hline Sichuan & 0.441 & 0.393 & 0.321 & 0.216 & 0.232 & 0.320 \\
\hline Guizhou & 0.301 & 0.301 & 0.238 & 0.495 & 0.526 & 0.372 \\
\hline Yunnan & 0.193 & 0.189 & 0.190 & 0.129 & 0.113 & 0.163 \\
\hline Shaanxi & 0.331 & 0.302 & 0.261 & 0.271 & 0.287 & 0.290 \\
\hline Gansu & 0.410 & 0.505 & 0.447 & 0.413 & 0.402 & 0.436 \\
\hline Qinghai & 0.328 & 0.225 & 0.171 & 0.185 & 0.218 & 0.226 \\
\hline Ningxia & 0.316 & 0.327 & 0.287 & 0.492 & 0.608 & 0.406 \\
\hline Xinjiang & 0.283 & 0.287 & 0.231 & 0.233 & 0.233 & 0.253 \\
\hline
\end{tabular}

region of China, which is similar to the comprehensive MEA efficiency. Most of the regional energy and $\mathrm{CO}_{2}$ emissions MEA efficiency are under 0.5. The results make it clear that larger parts of the regions in China are not performing MEA efficiently on energy and $\mathrm{CO}_{2}$ emissions in the transportation sector. Therefore, there lies a great potential to reduce the energy consumption and $\mathrm{CO}_{2}$ emission in each region. Also we notice a strange phenomenon that some regions have correspondingly high energy MEA efficiency but a low $\mathrm{CO}_{2}$ emissions MEA efficiency, for example, Inner Mongolia. It indicates that the resource of inefficiency is from $\mathrm{CO}_{2}$ emissions inefficiency. From the relative variable specific MEA efficiency illustrated in Table 6, we can detect the reasons of inefficiency in each region, and the decision marker can draw up the relevant policies and measures to improve the relative energy or $\mathrm{CO}_{2}$ emissions efficiency separately.

After we have the relative variable specific MEA efficiency (i.e., energy and $\mathrm{CO}_{2}$ emissions relative efficiencies), we are able to investigate the efficiency of three major areas during 2006-2010. Figure 2 demonstrates the annual average energy efficiency and $\mathrm{CO}_{2}$ emissions efficiency for China and its three major areas in the transportation sector. It seems that both the variable specific efficiencies of China and its three major areas overall experienced a process of first decreasing and then increasing over the study period. In Figure 2, we are able to see that the east area and central area have higher MEA efficiencies than west area on both the two variable specific efficiencies. However, the MEA efficiency difference of energy and $\mathrm{CO}_{2}$ emissions is mixed between the east China and the central China. We find that the east China performs better than central China on MEA efficiency of $\mathrm{CO}_{2}$ emissions during 2006-2010. But for MEA efficiency of energy, the east China has lower MEA efficiency score than central China during 2006-2008, and it is just opposite in 2009 and 2010. Therefore it can be concluded that the higher comprehensive MEA efficiency dominance of the east China over the central China and west China results from both the higher energy and $\mathrm{CO}_{2}$ emissions variable specific efficiency.

3.4. Efficiency Related Reduction Potentials on Energy and $\mathrm{CO}_{2}$ Emissions of China's Region in Transportation Sector. 
TABLE 6: Regional energy and $\mathrm{CO}_{2}$ emissions MEA efficiency of China (2006-2010).

\begin{tabular}{|c|c|c|c|c|c|c|c|c|c|c|}
\hline \multirow{2}{*}{ Region } & \multicolumn{5}{|c|}{ Energy } & \multicolumn{5}{|c|}{$\mathrm{CO}_{2}$ emissions } \\
\hline & 2006 & 2007 & 2008 & 2009 & 2010 & 2006 & 2007 & 2008 & 2009 & 2010 \\
\hline Beijing & 0.519 & 0.427 & 0.340 & 0.309 & 0.370 & 0.510 & 0.424 & 0.338 & 0.306 & 0.362 \\
\hline Tianjin & 0.529 & 0.550 & 0.488 & 0.570 & 1.000 & 0.506 & 0.529 & 0.468 & 0.543 & 0.615 \\
\hline Hebei & 1.000 & 1.000 & 1.000 & 1.000 & 1.000 & 1.000 & 1.000 & 1.000 & 1.000 & 1.000 \\
\hline Shanxi & 0.725 & 0.727 & 0.346 & 0.324 & 0.392 & 0.763 & 0.768 & 0.339 & 0.315 & 0.391 \\
\hline Inner Mongolia & 1.000 & 1.000 & 1.000 & 1.000 & 1.000 & 0.392 & 0.363 & 0.357 & 0.322 & 0.322 \\
\hline Liaoning & 0.323 & 0.292 & 0.298 & 0.269 & 0.306 & 0.308 & 0.278 & 0.282 & 0.252 & 0.286 \\
\hline Jilin & 0.598 & 0.458 & 0.383 & 0.350 & 0.371 & 0.563 & 0.427 & 0.364 & 0.330 & 0.346 \\
\hline Heilongjiang & 1.000 & 0.437 & 0.482 & 0.408 & 1.000 & 0.415 & 0.409 & 0.461 & 0.376 & 0.411 \\
\hline Shanghai & 0.300 & 0.254 & 0.239 & 1.000 & 1.000 & 0.283 & 0.239 & 0.224 & 0.156 & 0.247 \\
\hline Jiangsu & 0.697 & 0.634 & 0.593 & 1.000 & 1.000 & 0.667 & 0.605 & 0.568 & 0.542 & 1.000 \\
\hline Zhejiang & 0.522 & 0.492 & 0.463 & 0.415 & 0.465 & 0.500 & 0.471 & 0.441 & 0.392 & 0.441 \\
\hline Anhui & 1.000 & 1.000 & 1.000 & 0.517 & 0.517 & 0.831 & 0.711 & 0.697 & 0.491 & 0.488 \\
\hline Fujian & 1.000 & 1.000 & 1.000 & 0.548 & 1.000 & 0.893 & 0.820 & 0.642 & 0.515 & 0.535 \\
\hline Jiangxi & 0.636 & 0.605 & 0.624 & 0.532 & 0.494 & 0.603 & 0.573 & 0.592 & 0.504 & 0.469 \\
\hline Shandong & 1.000 & 1.000 & 1.000 & 1.000 & 1.000 & 1.000 & 1.000 & 1.000 & 1.000 & 0.578 \\
\hline Henan & 0.882 & 0.784 & 0.899 & 0.523 & 0.493 & 0.894 & 0.779 & 0.895 & 0.512 & 0.480 \\
\hline Hubei & 0.301 & 0.277 & 1.000 & 0.272 & 1.000 & 0.286 & 0.261 & 0.252 & 0.252 & 0.285 \\
\hline Hunan & 0.465 & 0.421 & 0.496 & 0.452 & 0.480 & 0.456 & 0.411 & 0.483 & 0.430 & 0.460 \\
\hline Guangdong & 0.416 & 0.378 & 0.353 & 0.333 & 0.344 & 0.398 & 0.361 & 0.336 & 0.314 & 0.325 \\
\hline Guangxi & 0.344 & 0.332 & 0.339 & 0.272 & 0.316 & 0.324 & 0.312 & 0.316 & 0.252 & 0.295 \\
\hline Hainan & 0.336 & 0.321 & 0.225 & 0.157 & 1.000 & 0.318 & 0.302 & 0.210 & 0.145 & 0.155 \\
\hline Chongqing & 0.523 & 0.387 & 0.361 & 0.367 & 0.339 & 0.497 & 0.365 & 0.340 & 0.346 & 0.317 \\
\hline Sichuan & 0.471 & 0.395 & 0.352 & 0.237 & 0.276 & 0.461 & 0.386 & 0.338 & 0.225 & 0.267 \\
\hline Guizhou & 0.346 & 0.308 & 0.244 & 0.454 & 0.472 & 0.350 & 0.309 & 0.238 & 0.445 & 0.459 \\
\hline Yunnan & 0.206 & 0.189 & 0.189 & 0.128 & 0.111 & 0.196 & 0.179 & 0.180 & 0.120 & 0.103 \\
\hline Shaanxi & 0.444 & 0.378 & 0.311 & 0.257 & 0.263 & 0.446 & 0.381 & 0.303 & 0.252 & 0.258 \\
\hline Gansu & 0.451 & 0.489 & 0.419 & 0.342 & 0.330 & 0.459 & 0.513 & 0.433 & 0.348 & 0.341 \\
\hline Qinghai & 0.612 & 0.354 & 0.259 & 0.242 & 0.268 & 0.609 & 0.333 & 0.251 & 0.222 & 0.252 \\
\hline Ningxia & 0.280 & 0.259 & 0.270 & 0.396 & 0.516 & 0.268 & 0.252 & 0.262 & 0.387 & 0.514 \\
\hline Xinjiang & 0.259 & 0.237 & 0.229 & 0.223 & 0.222 & 0.248 & 0.228 & 0.217 & 0.210 & 0.208 \\
\hline
\end{tabular}

By applying the MEA approach, we are able to measure the energy and $\mathrm{CO}_{2}$ emissions variable specific efficiency for each region of China in the transportation sector, and, based on the DEA theory, the inefficient regions can become efficient on each of their input and desirable and undesirable output variable so as to reach the benchmark by adjusting improvement potential associated with each variable. Therefore, in this section, we will further use the MEA approach to survey the energy conservation and $\mathrm{CO}_{2}$ emissions reduction potential for China's different regions during our study period.

From model (5), we know that the potential saving of each input variable is able to be calculated as $\beta_{i o}\left(x_{i o}-d_{i o}^{*}\right)$, the target value of each input variables after improvement potential adjustment is $x_{i o}-\beta_{i o}\left(x_{i o}-d_{i o}^{*}\right)$, the potential redundancy of $\mathrm{CO}_{2}$ emissions could be calculated as $\beta_{k i}\left(c_{k o}-\right.$ $\left.\varphi_{k o}^{*}\right)$, and the target of $\mathrm{CO}_{2}$ emissions after improvement potential adjustment is $c_{k o}-\beta_{k o}\left(c_{k o}-\varphi_{k o}^{*}\right)$. Table 7 documents the energy conservation potential and $\mathrm{CO}_{2}$ emissions reduction potential for China's each region in transportation sector during 2006-2010. In Table 7, we can see that the energy conservation potential and $\mathrm{CO}_{2}$ emissions reduction potential of each region are great in the transportation sector. For the energy conservation potential, there are ten out of 30 regions: Hebei, Inner Mongolia, Heilongjiang, Shanghai, Jiangsu, Anhui, Fujian, Shandong, Hubei, and Hainan, which do not have the improvement potential of energy for at least 1 year during our study period. But for $\mathrm{CO}_{2}$ emissions reduction potential, only two regions, namely, Inner Mongolia and Shandong do not have the improvement potential of $\mathrm{CO}_{2}$ emissions for at least 1 year during our study period. Only Hebei and Shandong have no improvement potential of energy and $\mathrm{CO}_{2}$ emissions simultaneously except 2010's improvement potential of $\mathrm{CO}_{2}$ emissions in Shandong. From an area perspective, we can further investigate the reduction potentials of energy saving and $\mathrm{CO}_{2}$ emissions reduction of three major areas from 2006 to 2010, which are illustrated in Figure 3. In short, as shown in Figure 3, the total energy conservation potential of China's transportation sector on the whole keeps first increasing and then decreasing 


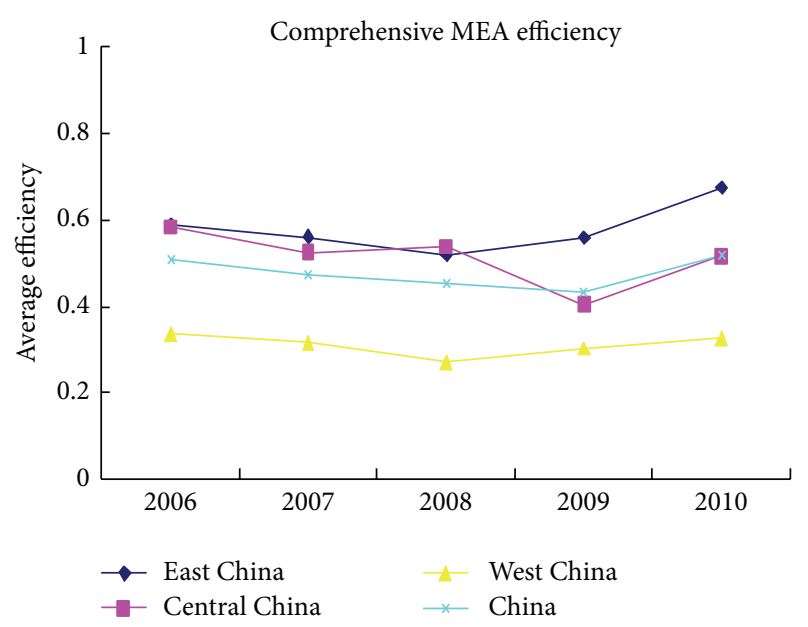

FIGURE 1: Average comprehensive MEA efficiency of China and its three major areas.

beginning from 2009 during the study period. But the total $\mathrm{CO}_{2}$ emissions reduction potential of China's transportation sector always keeps an increasing trend. In general, east China has the largest energy conservation and $\mathrm{CO}_{2}$ emissions reduction potentials, and those of west China are the smallest.

For the sake of a detailed description, we will take the relative data in 2010 as an example to analyze the regional energy conservation potential and $\mathrm{CO}_{2}$ emissions reduction potential in China's transportation sector. As is shown in Table 7, there are eight regions whose theoretical maximum energy conservation potentials are more than five million TCEs in 2010. In these eight regions, Guangdong has the largest energy conservation potential, followed by Liaoning, Yunnan, Sichuan, Shaanxi, Zhejiang, Beijing, and Guangxi. Furthermore, another ten regions have zero energy conservation potential because they are efficient regions such as Tianjin, Hebei, Inner Mongolia, Heilongjiang, Shanghai, Jiangsu, Fujian, Shandong, Hubei, and Hunan. We see that most of these 10 regions are located in east China and they are all energy specific efficient regions in China. Among the inefficient regions, Guangdong has the largest energy conservation potential, but its energy MEA efficiency was not the lowest. On the contrary, Yunnan, Xinjiang, Shaanxi, Qinghai, Sichuan, Liaoning, Guangxi, Gansu, and Chongqing have lower energy MEA efficiency in 2010. Also we find that these 8 regions are located in west China except Liaoning and Guangxi. The above results point out that these inefficient regions which have a great energy conservation potential and a low energy MEA efficiency should pay more attention to their energy consumption control policy and energy efficiency promotion, so as to increase their energy saving and promote their energy utilization performances and catch up with the high efficiency benchmark regions.

Table 7 also illustrates similar assessment results on the potentials of $\mathrm{CO}_{2}$ emissions reduction for China's regions in transportation sector in 2010. From Table 7, we see that Guangdong, Shanghai, Liaoning, and Shandong whose potentials of $\mathrm{CO}_{2}$ emissions reduction are larger than 20 million TCEs rank highly in China in 2010 and Guangdong has the largest potential of $\mathrm{CO}_{2}$ emissions reduction. But its $\mathrm{CO}_{2}$ emissions MEA efficiency was not the lowest. On the contrary, Yunnan, Hainan, Xinjiang, Shanghai, Qinghai, and Shaanxi have lower energy MEA efficiency in 2010. Besides, we find that these regions are located in west China except Hainan and Shanghai. The regions with unit $\mathrm{CO}_{2}$ emissions MEA efficiency and zero $\mathrm{CO}_{2}$ emissions reduction potentials such as Hebei and Jiangsu are the same as the benchmark regions under energy specific efficiency assessment. The above results show that the regions of greater $\mathrm{CO}_{2}$ emissions reduction potentials should be given higher priority to $\mathrm{CO}_{2}$ emissions controls to improve their $\mathrm{CO}_{2}$ emissions MEA efficiency, reduce $\mathrm{CO}_{2}$ emissions redundancies, and catch up with the highly performed benchmark regions.

\section{Conclusion}

In recent years, an increasing number of studies have applied DEA approach to evaluate energy or environmental efficiency; however, there are rare studies which pay close attention to China's transportation sector. In this study, we propose a combination model of nonradial DEA and MEA, focusing on the measurement of regional energy and environmental efficiency of China's transportation sector during the period 2006-2010. Not only the energy and environmental efficiency levels and trend of China's transportation sector are investigated but also the efficiency patterns of China's 30 regions and three major areas are investigated. In addition, the energy saving potential and $\mathrm{CO}_{2}$ emissions reduction potential for each province and area in China are identified in this study.

With all the models, we can draw the conclusions as follows. (i) Most of regions whose average comprehensive MEA efficiency is below 0.5 during 2006-2010 tell us that many regions in China are not efficient in the transportation sector. (ii) From an area perspective, the regions in east China had the highest average comprehensive MEA efficiency, followed by the regions in central China and then the regions in west China. The comprehensive MEA efficiency of the east area surpassing the other two areas is due to the higher emission and energy specific efficiency except 2006-2008. (iii) During the period from 2006 to 2010, the trend of the comprehensive MEA slightly decreases from 2006 to 2009 and then begins to increase, and the average energy and emission efficiency have the same trend as the comprehensive MEA. (iv) Up to 2010, China's transportation sector still has great energy conservation potential and $\mathrm{CO}_{2}$ emissions reduction potential; the central government should keep on implementing strict policies for energy consumption and $\mathrm{CO}_{2}$ emissions to develop more ecofriendly transportation industry.

Our empirical study also has some significant policy implications. First of all, the regional imbalances are narrowed in China's transportation sector, so the government should pay greater attention to the central and the west area whose transportation facilities are relatively undeveloped. 
TABLE 7: Regional energy and $\mathrm{CO}_{2}$ emissions reduction potential of China (2006-2010).

\begin{tabular}{|c|c|c|c|c|c|c|c|c|c|c|}
\hline \multirow{2}{*}{ Region } & \multicolumn{5}{|c|}{ Energy conservation potential } & \multicolumn{5}{|c|}{$\mathrm{CO}_{2}$ emissions reduction potential } \\
\hline & 2006 & 2007 & 2008 & 2009 & 2010 & 2006 & 2007 & 2008 & 2009 & 2010 \\
\hline Beijing & 294.0 & 415.2 & 550.3 & 600.6 & 586.8 & 6.1 & 8.4 & 11.0 & 11.9 & 11.9 \\
\hline Tianjin & 155.4 & 148.0 & 188.8 & 171.9 & 0.0 & 3.4 & 3.2 & 4.0 & 3.7 & 3.5 \\
\hline Hebei & 0.0 & 0.0 & 0.0 & 0.0 & 0.0 & 0.0 & 0.0 & 0.0 & 0.0 & 0.0 \\
\hline Shanxi & 114.4 & 116.1 & 505.6 & 526.9 & 490.0 & 1.9 & 1.9 & 10.3 & 10.8 & 9.6 \\
\hline Inner Mongolia & 0.0 & 0.0 & 0.0 & 0.0 & 0.0 & 9.1 & 11.0 & 12.8 & 15.4 & 17.4 \\
\hline Liaoning & 821.4 & 957.2 & 943.6 & 1035.3 & 1019.1 & 17.5 & 20.4 & 20.2 & 22.1 & 21.8 \\
\hline Jilin & 110.2 & 200.6 & 288.5 & 306.1 & 307.1 & 2.5 & 4.5 & 6.2 & 6.6 & 6.7 \\
\hline Heilongjiang & 0.0 & 289.5 & 233.3 & 303.5 & 0.0 & 6.3 & 6.4 & 5.0 & 6.8 & 6.4 \\
\hline Shanghai & 1080.3 & 1304.9 & 1377.3 & 0.0 & 0.0 & 23.4 & 28.2 & 29.6 & 32.5 & 30.7 \\
\hline Jiangsu & 279.4 & 369.7 & 469.1 & 0.0 & 0.0 & 6.4 & 8.3 & 10.3 & 11.3 & 0.0 \\
\hline Zhejiang & 398.7 & 469.0 & 537.4 & 603.7 & 599.6 & 8.7 & 10.2 & 11.6 & 13.0 & 12.9 \\
\hline Anhui & 0.0 & 0.0 & 0.0 & 211.0 & 238.3 & 1.2 & 2.4 & 2.6 & 4.6 & 5.2 \\
\hline Fujian & 0.0 & 0.0 & 0.0 & 299.4 & 0.0 & 0.9 & 1.8 & 4.5 & 6.7 & 7.2 \\
\hline Jiangxi & 121.2 & 135.6 & 129.7 & 168.0 & 221.0 & 2.8 & 3.1 & 2.9 & 3.7 & 4.8 \\
\hline Shandong & 0.0 & 0.0 & 0.0 & 0.0 & 0.0 & 0.0 & 0.0 & 0.0 & 0.0 & 21.4 \\
\hline Henan & 68.4 & 146.6 & 72.4 & 362.9 & 434.8 & 1.2 & 3.0 & 1.5 & 7.4 & 8.9 \\
\hline Hubei & 683.5 & 770.6 & 0.0 & 830.4 & 0.0 & 14.6 & 16.6 & 19.2 & 18.0 & 17.9 \\
\hline Hunan & 339.4 & 404.2 & 298.6 & 412.7 & 436.0 & 7.0 & 8.4 & 6.2 & 8.8 & 9.2 \\
\hline Guangdong & 1081.6 & 1270.5 & 1423.2 & 1541.2 & 1681.4 & 23.2 & 27.2 & 30.4 & 32.9 & 35.7 \\
\hline Guangxi & 344.0 & 384.8 & 392.9 & 490.0 & 503.4 & 7.5 & 8.4 & 8.6 & 10.6 & 10.9 \\
\hline Hainan & 100.8 & 112.5 & 186.3 & 229.8 & 0.0 & 2.2 & 2.4 & 4.0 & 5.0 & 5.2 \\
\hline Chongqing & 163.4 & 259.0 & 307.3 & 289.8 & 368.3 & 3.6 & 5.7 & 6.7 & 6.2 & 7.9 \\
\hline Sichuan & 349.9 & 481.8 & 585.8 & 809.1 & 730.0 & 7.3 & 9.9 & 12.3 & 17.0 & 14.9 \\
\hline Guizhou & 175.6 & 227.0 & 314.2 & 232.4 & 259.7 & 3.4 & 4.5 & 6.4 & 4.7 & 5.4 \\
\hline Yunnan & 470.1 & 518.0 & 532.7 & 588.6 & 751.1 & 10.0 & 11.0 & 11.2 & 12.4 & 15.9 \\
\hline Shaanxi & 244.0 & 315.5 & 437.6 & 591.6 & 642.0 & 4.8 & 6.2 & 9.0 & 11.9 & 12.9 \\
\hline Gansu & 143.0 & 135.8 & 164.0 & 198.8 & 222.7 & 2.8 & 2.5 & 3.1 & 3.8 & 4.2 \\
\hline Qinghai & 15.5 & 45.9 & 65.4 & 74.4 & 80.8 & 0.3 & 1.0 & 1.3 & 1.6 & 1.7 \\
\hline Ningxia & 89.8 & 98.1 & 96.5 & 84.7 & 72.9 & 1.9 & 2.0 & 2.0 & 1.7 & 1.5 \\
\hline Xinjiang & 327.4 & 351.1 & 361.6 & 351.9 & 378.1 & 6.9 & 7.3 & 7.7 & 7.4 & 8.0 \\
\hline
\end{tabular}
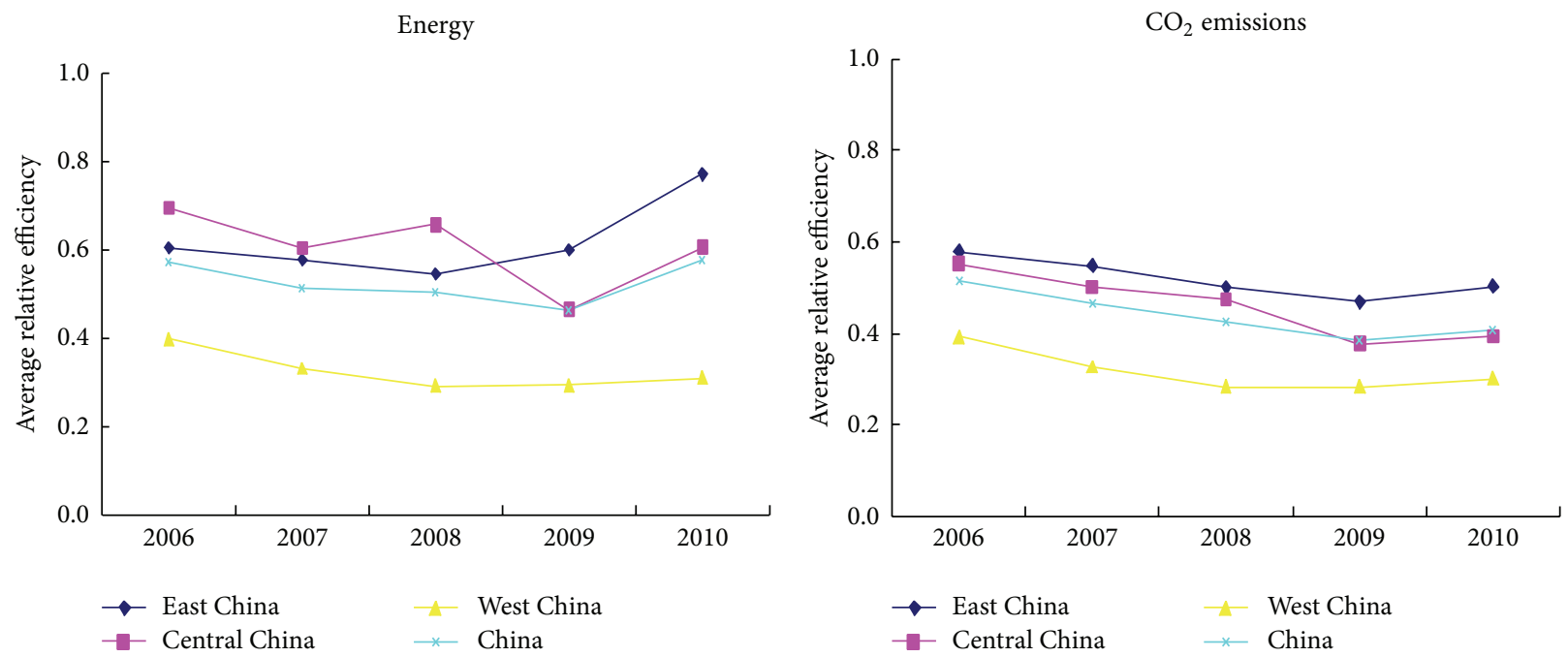

Figure 2: Average relative variable specific efficiencies of China and its three areas (2006-2010). 

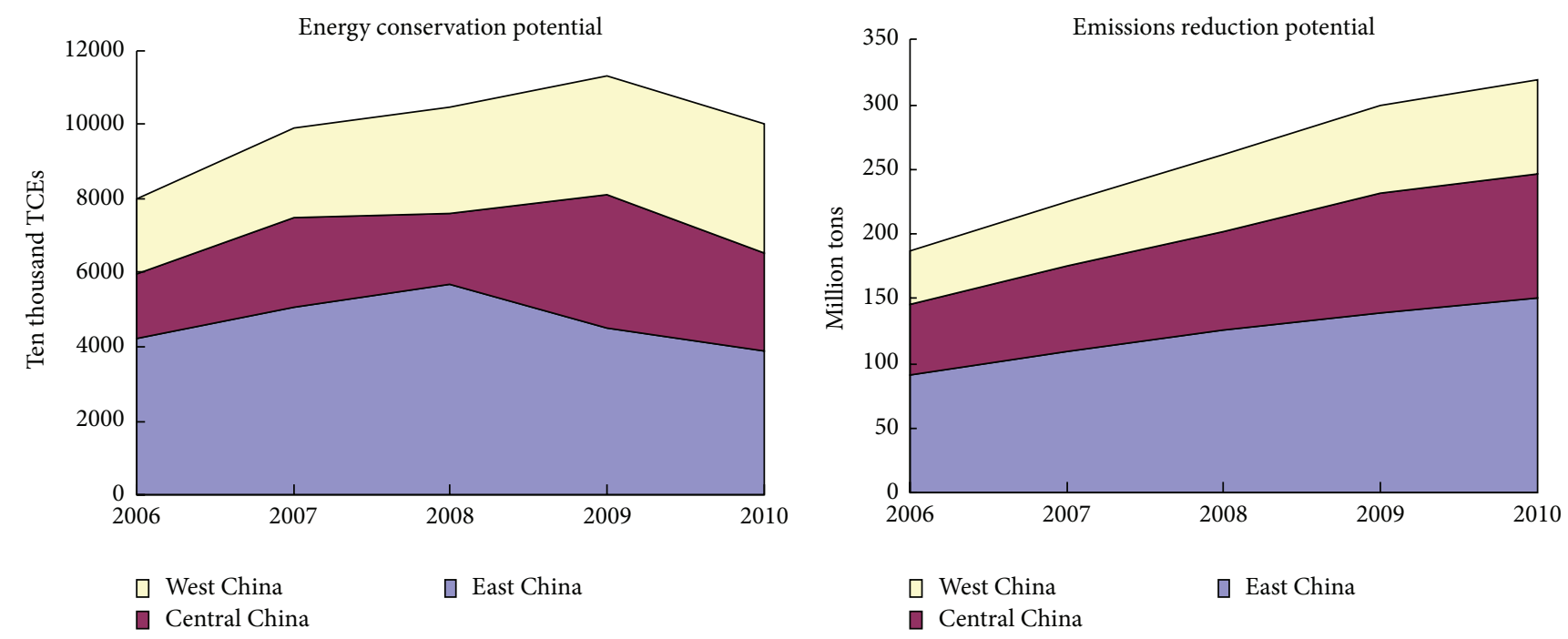

FIgURE 3: MEA relative energy conservation and $\mathrm{CO}_{2}$ emissions reduction potentials of China's three areas (2006-2010).

Secondly, the related policies to encourage public transportation and control individual transportation guide huge energy conservation potential and $\mathrm{CO}_{2}$ emissions reduction potential in some big cities in east China. Furthermore, we should give impetus to transportation technological innovation and promote vehicle emission standards and explore alternative transport energy which has a great advantage to reduce energy consumption and $\mathrm{CO}_{2}$ emissions reduction.

This study only compares energy and environmental efficiency of the transportation sector among the Chinese provinces. If the data includes other advanced countries, for instance, OECD countries, it may provide more information on the level of China's transportation sector. Also this research can be combined with Malmquist Productivity Index to investigate the technical efficiency change of China's transportation sectors. All these remain avenues for future research.

\section{Conflict of Interests}

The authors declare that there is no conflict of interests regarding the publication of this paper.

\section{Acknowledgments}

The authors thank the anonymous reviewers for their valuable comments. In addition, the financial support from the National Natural Science Foundation of China (71171181, 71322101, 71271195, and 71121061), the Ministry of Education of China (NCET-10-0993), and USTC Fund for Innovation Teams (WK2040160008) is acknowledged.

\section{References}

[1] K. Wang, Y. M. Wei, and X. Zhang, "Energy and emissions efficiency of Chinese regions: a multidirectional efficiency analysis," Applied Energy, vol. 104, pp. 105-116, 2013.
[2] State Council of the People's Republic of China (SCPRC), The 12th Five Year Plan of China, 2011, (Chinese).

[3] W. Lu, "Potential energy savings and environmental impacts of energy efficiency standards for vapor compression central air conditioning units in China," Energy Policy, vol. 35, no. 3, pp. 1709-1717, 2007.

[4] Y. Hu, "Implementation of voluntary agreements for energy efficiency in China," Energy Policy, vol. 35, no. 11, pp. 5541-5548, 2007.

[5] M. Watanabe and K. Tanaka, "Efficiency analysis of Chinese industry: a directional distance function approach," Energy Policy, vol. 35, no. 12, pp. 6323-6331, 2007.

[6] Y. Bian and F. Yang, "Resource and environment efficiency analysis of provinces in China: a DEA approach based on Shannon's entropy," Energy Policy, vol. 38, no. 4, pp. 1909-1917, 2010.

[7] T.-L. Yeh, T.-Y. Chen, and P.-Y. Lai, "A comparative study of energy utilization efficiency between Taiwan and China," Energy Policy, vol. 38, no. 5, pp. 2386-2394, 2010.

[8] K. Wang, S. Yu, and W. Zhang, "China's regional energy and environmental efficiency: a DEA window analysis based dynamic evaluation," Mathematical and Computer Modelling, vol. 58, no. 5-6, pp. 1117-1127, 2011.

[9] International Energy Agency, $\mathrm{CO}_{2}$ Emissions from Fuel Combustion, IEA, Paris, France, 2009.

[10] International Energy Agency, $\mathrm{CO}_{2}$ Emissions from Fuel Combustion Highlights, IEA, Cancun, Mexico, 2011.

[11] A. Charnes, W. W. Cooper, and E. Rhodes, "Measuring the efficiency of decision making units," European Journal of Operational Research, vol. 2, no. 6, pp. 429-444, 1978.

[12] W. W. Cooper, L. M. Seiford, and J. Zhu, Eds., Handbook on Data Envelopment Analysis, Kluwer Academic, London, UK, 2004.

[13] W. D. Cook and L. M. Seiford, "Data envelopment analysis (DEA) - thirty years on," European Journal of Operational Research, vol. 192, no. 1, pp. 1-17, 2009.

[14] P. Zhou, B. W. Ang, and K. L. Poh, "A survey of data envelopment analysis in energy and environmental studies," European Journal of Operational Research, vol. 189, no. 1, pp. 1-18, 2008. 
[15] J.-L. Hu and S.-C. Wang, "Total-factor energy efficiency of regions in China," Energy Policy, vol. 34, no. 17, pp. 3206-3217, 2006.

[16] B. Zhang, J. Bi, Z. Fan, Z. Yuan, and J. Ge, "Eco-efficiency analysis of industrial system in China: a data envelopment analysis approach," Ecological Economics, vol. 68, no. 1-2, pp. 306-316, 2008.

[17] G.-M. Shi, J. Bi, and J.-N. Wang, "Chinese regional industrial energy efficiency evaluation based on a DEA model of fixing non-energy inputs," Energy Policy, vol. 38, no. 10, pp. 6172-6179, 2010.

[18] K. Wang, Y.-M. Wei, and X. Zhang, "A comparative analysis of China's regional energy and emission performance: Which is the better way to deal with undesirable outputs?" Energy Policy, vol. 46, pp. 574-584, 2012.

[19] Q. Wang, P. Zhou, and D. Zhou, "Efficiency measurement with carbon dioxide emissions: the case of China," Applied Energy, vol. 90, no. 1, pp. 161-166, 2012.

[20] L. Wang, L. Xu, and H. Song, "Environmental performance evaluation of Beijing's energy use planning," Energy Policy, vol. 39, no. 6, pp. 3483-3498, 2011.

[21] Z.-H. Wang, H.-L. Zeng, Y.-M. Wei, and Y.-X. Zhang, "Regional total factor energy efficiency: an empirical analysis of industrial sector in China," Applied Energy, vol. 97, pp. 115-123, 2012.

[22] F. Wu, L. W. Fan, P. Zhou, and D. Q. Zhou, "Industrial energy efficiency with $\mathrm{CO}_{2}$ emissions in China: a nonparametric analysis," Energy Policy, vol. 49, pp. 164-172, 2012.

[23] Y. Choi, N. Zhang, and P. Zhou, "Efficiency and abatement costs of energy-related $\mathrm{CO}_{2}$ emissions in China: a slacks-based efficiency measure," Applied Energy, vol. 98, pp. 198-208, 2012.

[24] M. Asmild and K. Matthews, "Multi-directional efficiency analysis of efficiency patterns in Chinese banks 1997-2008," European Journal of Operational Research, vol. 219, no. 2, pp. 434-441, 2012.

[25] R. Fare, S. Grosskopf, C. A. K. Lovell, and C. Pasurka, "Multilateral productivity comparisons when some outputs are undesirable: a nonparametric approach," The Review of Economics and Statistics, vol. 71, pp. 90-98, 1989.

[26] P. Zhou, B. W. Ang, and H. Wang, "Energy and $\mathrm{CO}_{2}$ emission performance in electricity generation: a non-radial directional distance function approach," European Journal of Operational Research, vol. 221, pp. 625-635, 2012.

[27] H. Fukuyama and W. L. Weber, "A directional slacks-based measure of technical inefficiency," Socio-Economic Planning Sciences, vol. 43, no. 4, pp. 274-287, 2009.

[28] P. Zhou, K. L. Poh, and B. W. Ang, "A non-radial DEA approach to measuring environmental performance," European Journal of Operational Research, vol. 178, no. 1, pp. 1-9, 2007.

[29] H. Fukuyama, Y. Yoshida, and S. Managi, "Modal choice between air and rail: a social efficiency benchmarking analysis that considers $\mathrm{CO}_{2}$ emissions," Environmental Economics and Policy Studies, vol. 13, no. 2, pp. 89-102, 2011.

[30] C. P. Barros, S. Managi, and R. Matousek, "The technical efficiency of the Japanese banks: non-radial directional performance measurement with undesirable output," Omega, vol. 40, no. 1, pp. 1-8, 2012.

[31] R. Ramanathan, "A holistic approach to compare energy efficiencies of different transport modes," Energy Policy, vol. 28, no. 11, pp. 743-747, 2000.

[32] J. Tongzon, "Efficiency measurement of selected Australian and other international ports using data envelopment analysis,"
Transportation Research A: Policy and Practice, vol. 35, no. 2, pp. 107-122, 2001.

[33] R. Färe, S. Grosskopf, D.-W. Noh, and W. Weber, "Characteristics of a polluting technology: theory and practice," Journal of Econometrics, vol. 126, no. 2, pp. 469-492, 2005.

[34] P. Bogetoft and J. L. Hougaard, "Efficiency evaluations based on potential (non-proportional) improvements," Journal of Productivity Analysis, vol. 12, no. 3, pp. 233-247, 1999.

[35] P. Bogetoft and J. L. Hougaard, "Super efficiency evaluations based on potential slack," European Journal of Operational Research, vol. 152, no. 1, pp. 14-21, 2004.

[36] M. Asmild and J. T. Pastor, "Slack free MEA and RDM with comprehensive efficiency measures," Omega, vol. 38, no. 6, pp. 475-483, 2010.

[37] M. Asmild, T. Holvad, J. L. Hougaard, and D. Kronborg, "Railway reforms: do they influence operating efficiency?" Transportation, vol. 36, no. 5, pp. 617-638, 2009.

[38] T. Holvad, J. L. Hougaard, D. Kronborg, and H. K. Kvist, "Measuring inefficiency in the Norwegian bus industry using multi-directional efficiency analysis," Transportation, vol. 31, no. 3, pp. 349-369, 2004.

[39] R. Färe and C. A. Knox Lovell, "Measuring the technical efficiency of production," Journal of Economic Theory, vol. 19, no. 1, pp. 150-162, 1978.

[40] A. Charnes, W. W. Cooper, B. Golany, L. Seiford, and J. Stutz, "Foundations of data envelopment analysis for ParetoKoopmans efficient empirical production functions," Journal of Econometrics, vol. 30, no. 1-2, pp. 91-107, 1985.

[41] C. A. Knox Lovell, J. T. Pastor, and J. A. Turner, "Measuring macroeconomic performance in the OECD: a comparison of European and non-European countries," European Journal of Operational Research, vol. 87, no. 3, pp. 507-518, 1995.

[42] W. W. Cooper, K. S. Park, and J. T. Pastor, "RAM: a range adjusted measure of inefficiency for use with additive models, and relations to other models and measures in DEA," Journal of Productivity Analysis, vol. 11, no. 1, pp. 5-42, 1999.

[43] J. T. Pastor, J. L. Ruiz, and I. Sirvent, "An enhanced DEA Russell graph efficiency measure," European Journal of Operational Research, vol. 115, no. 3, pp. 596-607, 1999.

[44] K. Tone, "A slacks-based measure of super-efficiency in data envelopment analysis," European Journal of Operational Research, vol. 143, no. 1, pp. 32-41, 2002.

[45] J. Zhu, "Data envelopment analysis vs. principal component analysis: an illustrative study of economic performance of Chinese cities," European Journal of Operational Research, vol. 111, no. 1, pp. 50-61, 1998.

[46] C.-C. Lee, "Energy consumption and GDP in developing countries: a cointegrated panel analysis," Energy Economics, vol. 27, no. 3, pp. 415-427, 2005.

[47] National Bureau of Statistics of China (NBSC), China Energy Statistical Year Book, China Statistics Press, Beijing, China, 2007b-2011b.

[48] National Bureau of Statistics of China (NBSC), China Statistical Year Book, China Statistics Press, Beijing, China, 2007a-2011a.

[49] IPCC, "IPCC Guidelines for National Greenhouse Gas Inventories," 2006, http://www.ipcc-nggip.iges.or.jp/public/ 2006gl/vol2.html.

[50] National Development and Reform Commission (NDRC), National Greenhouse Gas Inventory of the People's Republic of China, Chinese Environmental Science Press, Beijing, China, 2007, (Chinese). 


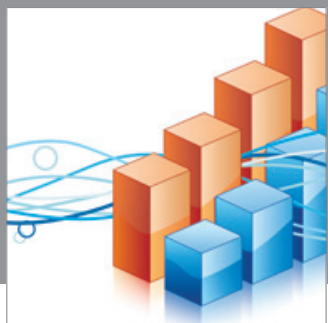

Advances in

Operations Research

mansans

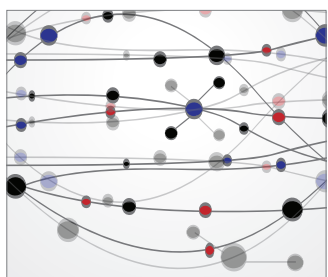

The Scientific World Journal
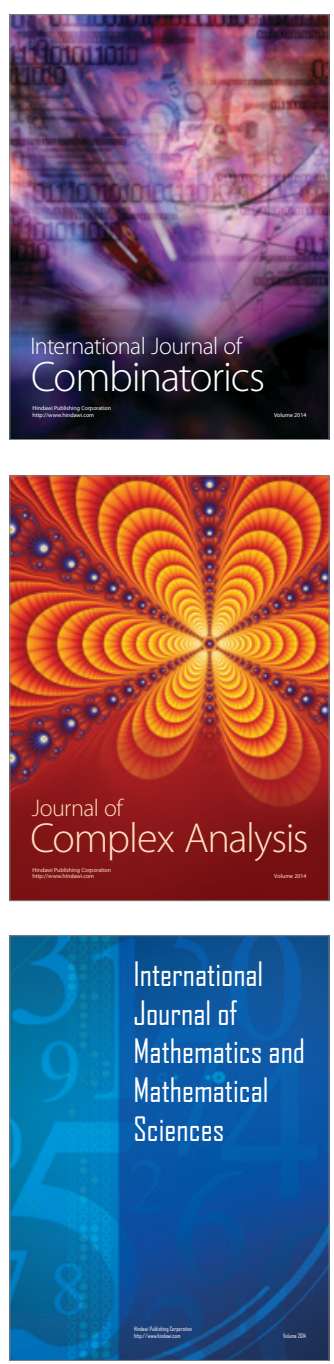
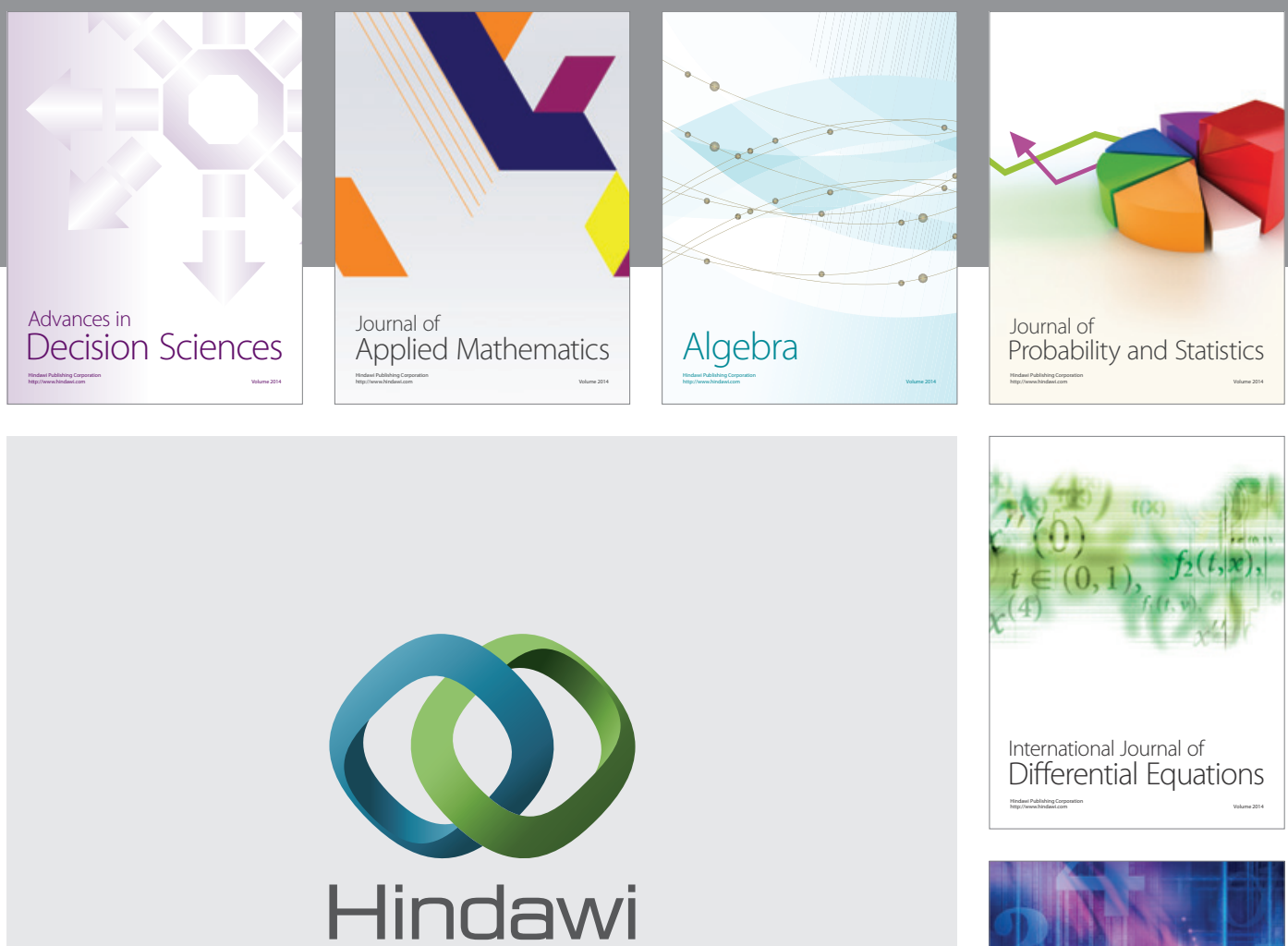

Submit your manuscripts at http://www.hindawi.com
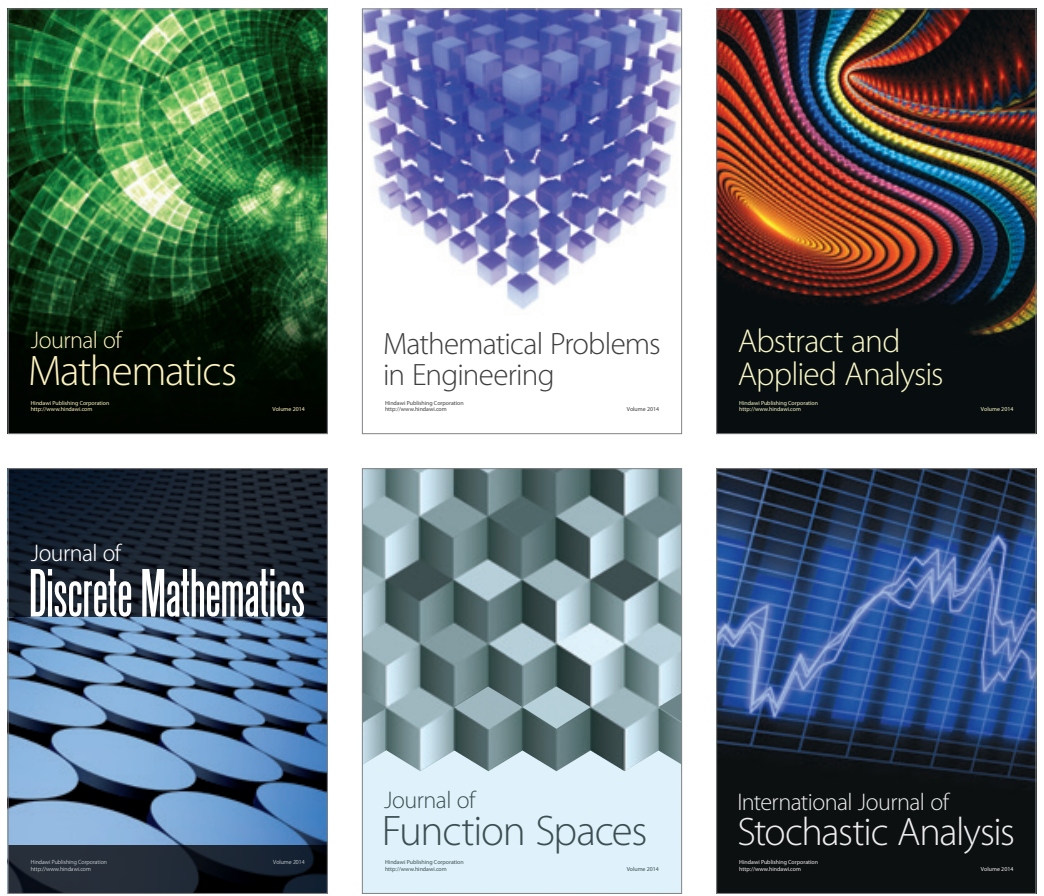

Journal of

Function Spaces

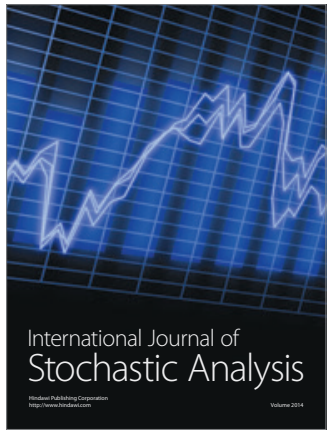

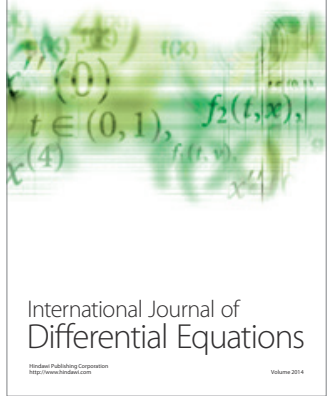
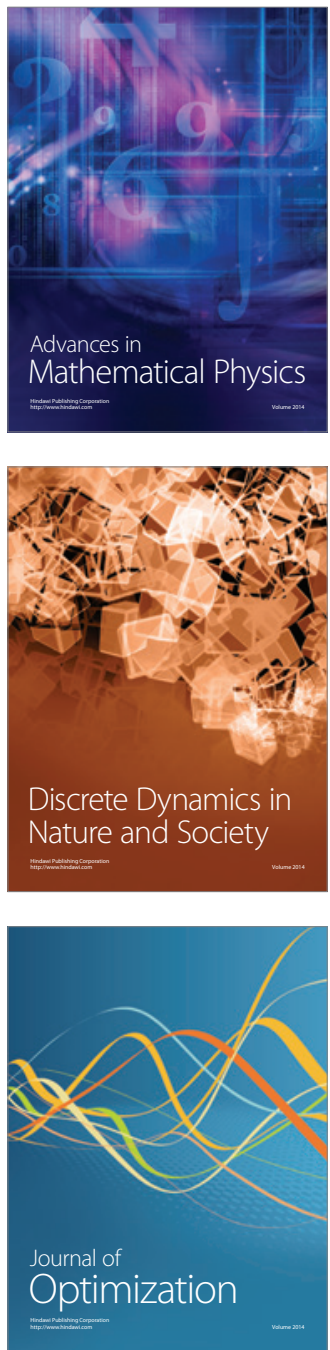